\title{
RESEARCH PAPER \\ THE POTENTIALITY OF LEATHER AS ALTERNATIVE MATERIAL FOR SUSTAINING MASK PRODUCTION IN GHANA
}

\author{
J. O. B. Boahin, ${ }^{*}$ K. Asubonteng and V. Adu-Gyamfi \\ Department of Integrated Rural Art and Industry, College of Art and Social Sciences \\ KNUST, Kumasi \\ *Corresponding author: jboahin@gmail.com
}

\begin{abstract}
This study explored the viability of the Ghanaian indigenous vegetable tanned leather for the production of aesthetic masks for ornamental purposes. The study was basically experimental, and all processes were observed and recorded carefully for analysis. Modeling technique was principally used in three experiments to produce masks with three different thicknesses of leather acquired from cow hides. The thicknesses were purposively selected. The outcome of the study has confirmed the versatility of leather as alternative material for mask production. The study has strategically created another impetus in diversifying and expanding the utility of Ghanaian indigenous vegetable tanned leather aside the conventional usage for making bags, sandals and footrests.
\end{abstract}

Keywords: Leather, Mask, Alternative Material, Sustainability

\section{INTRODUCTION}

Wood has been an important material for mask production in Ghana, particularly among carvers at Ahwia in the Ashanti, Aburi in the Eastern Region and other parts of the country. Unfortunately, due to excessive demand for wood, accelerated rate of deforestation and poor forest management practices, the country is currently experiencing scarcity and near extinction of some wood species suitable for carving quality masks. This has therefore resulted in the high cost of wood for mask production, and conse- quently soaring prices of wooden mask, leading to low patronage of wooden masks on the market. Some mask carvers have resorted to using far cheaper and inferior wood species that are not durable. The situation is detrimental to the sustainability of wooden mask production. The wealth creation potentials of wooden mask production, as well as its economic contribution to the country's tourism sector is therefore under threat.

Considering the versatile properties of leather 
and how it lends itself to manipulation for diverse utility, this study found it expedient to explore the viability of the Ghanaian indigenous vegetable tanned leather for the production of masks for ornamental purposes. This will minimize the pressure on wood demand for mask carving, and consequently reduce deforestation in the country. The study sought to ascertain the response of leather to manipulations in mask production, with the ultimate aim of creating alternative material for the sustenance of the source of livelihood for mask carvers in the country.

The term 'mask' has varied sense of meanings in professional sectors such as science, medicine, arts, sports, warfare and tannery activities. According to the Collins English Dictionary (2008), a mask in general thoughts, is defined as an object normally worn on the face, typically for protection, disguise, concealing or entertainments. In the area of wood carving, mask as an artifact refers to a mold of a person's face, real facial expression or grotesque representation of a head, face or a covering resembling a face, used for hiding, ornamentation, ceremonial or practical purposes (Amenuke, 1995). Wearing a mask may also change the wearer's actions and other people's reactions to the wearer. This double impact is a basic characteristic of spiritual and ornamental masks, and is also what makes them so attractive for people to use, as has been discovered from antiquity to the present time.

The morphological elements of masks are, with few exceptions, derived from natural forms. Masks with human features are classified as having anthropomorphic characteristics, and in some instances, the mask form is a replication of natural features of animals or closely follows the lineaments of reality, and in other instances it is an abstraction. Masks usually represent supernatural beings, ancestors, and fanciful or imagined figures and can also be portraits.

Historically, the use of masks in rituals or ceremonies is a very ancient human practice across the world. Masks were worn for protection, in hunting, in sports, in feasts or in wars - or simply used as ornamentation. Some ceremonial or decorative masks were not designed to be worn. Although the religious use of mask has waned, its use in drama, therapy or psychotherapy and ornamentation is popular. In ancient Rome the word persona meant 'a mask'; it also referred to an individual who had full Roman citizenship. A citizen could demonstrate his or her lineage through images, such as, death masks of the ancestors. These were wax casts kept in a lararium of the family shrine. Rites of passage, such as initiation of young members of the family, or funerals, were carried out at the shrine under the watch of the ancestral masks. At funerals professional actors would wear these masks to perform deeds of the lives of the ancestors, thus linking the role of mask as a ritual object. In theatre, throughout the world, masks are used for their expressive power as a feature of masked performance - both ritually and in various theatre traditions. The ritual and theatrical definitions of mask usage frequently overlap and merge but still provide a useful basis for categorization.

In contemporary sense, mask production has exceeded its antique purpose with variations in materials used and functions served. Masks have been designed in innumerable varieties, from the simplest of crude "false faces" to realistic human facial representations. Mask production in Ghana has been carried out mainly in wood, although other materials including metal, Plaster of Paris (PoP), cement, fabric and clay are applicable. Wood species including Alstonnia boonei, Ceiba (Ceiba pentandra), Sese (Holarrhea wiufsbergii), and Mahogany (Khaya ivorensis) are mostly preferred for mask carving (Okrah, 2002). The preference of wood for mask production is basically due to its positive response to carving techniques such as blocking into shapes, forms and reliefs such as high, medium, low and sunking methods.

Agyeman (2010) has pointed out that different wood species possess several varied properties 
Viability of indigenous vegetable tanned leather for mask production...

desirable in the finished artifacts. Some of these properties include the grain structure, grain patterns, grain colour, hardness and firmness, porosity, and ability to season to required moisture content. In terms of aesthetics, wood surfaces can be sanded, polished, painted, sprayed, waxed or coated to enhance the appeal. Again, Agyeman (2010) has opined that there are several integrative materials and techniques which can be employed for embellishment on wood surfaces. Wood carvings including masks are usually adorned with metal pieces or fabric, but the use of leather is rare.

Ackah and Amankwah (2010), studied 15 galleries at the Kumasi Centre for National Culture and the Accra Art Center, and found that the patrons of Ghanaian indigenous artifacts mostly prefer wood carvings, textiles, leather and small metal goldsmith. Wooden masks were identified among the most purchased wood carvings by tourists. In the same vein, Darko (2006) confirmed that the wooden mask business was lucrative and served as a source of livelihood for the carvers. However, its sustainability is the major concern, considering the fast rate of forest depletion being experienced in the country.

For the purpose of mask production, leather is being considered in this study due to its diverse properties allowing manipulation into different shapes and art forms. The definition of leather poses difficulties to writers due to its varied properties which give the material insurmountable abilities for various possibilities. In simpler terms, leather as a material is pelt which has been subjected to chemical treatments to render it stable and resistant to putrefaction and shrinkage resulting from temperature. The entire process of leather making is called tanning, and it depends on tannages (chemicals) containing astringency for cross-linking collagen fibres of pelts into leather.

According to Sharphouse (1995), leather is a a material when well treated provides vast natural properties for various productions, alone or with other materials. Boahin (2008) has stated that unlike synthetic material, leather is versatile in utility due to its diverse properties; it has durability, workability and beauty that enhances with age. It possesses properties which give it the ability to stretch, to be as flexible as cloth or as stiff as wood, and some kinds are thick and heavy. Leather can be dyed and polished to have a glossy finish as expected. Anini et al. (2012) have also emphasized that a variety of decorative techniques including painting, dyeing, embossment, marbling and coating can be employed to beautify the aesthetic appeal of leather. Lawson (1990) also stresses that leather is obtained mostly from domestic animals, which are inexhaustible renewable natural resources, and regeneration only requires appropriate husbandry practices.

Leathers vary largely in properties from one animal to another, and Sharphouse (1995) explains that the reasons for the large differences in mechanical and physical characteristics of leather types originate partly from the natural structure of the skin and partly from the choice of the manufacturing process. This gives the material its versatile nature for utility in producing a variety of leather art forms such as containers, upholstery, footwear, clothing, office accessories and decoration. To employ leather in activities in three dimensional forms, mouldability, softness, pliability and stretchiness are required properties. Sharphouse (1995) has therefore emphasized that between the two basic classifications of tanning leather, - vegetable and mineral tanning methods - vegetable tanning techniques render the leather more mouldable than mineral tanning since the rate of rehydration is high and the fibers open up easily.

\section{METHODOLOGY}

The aim of the study was to explore the viability of the Ghanaian indigenous vegetable tanned leather as alternative material for the production of aesthetic masks in order to reduce the high dependency on wood as a raw material. The study adopted a studio based ex- 


\section{Boahin et al.}

perimentation approach which required the use of three different thicknesses of cow hide selected purposively. The hides measured 3.5 square feet each, and their thicknesses were $4 \mathrm{~mm}, 5 \mathrm{~mm}$ and $8 \mathrm{~mm}$. Two main activities were carried out in stages; preparing the hides into leather possessing the right properties and processing the leather into mask. Since leather is a soft material known for use in making flat surface artifacts, three dimensional mask moulds were needed to serve as support for the modeling. Wood, clay and Plaster of Paris (PoP) were selected for making moulds for the three experiments.

\section{Preparing the Hides for Modeling}

The hides were tanned by following the Ghanaian indigenous vegetable tanning method using astringents from Acacia nilotica pods acquired from northern Ghana. Systematically, the processes employed in the tanning were soaking, liming, defleshing, dehairing, deliming, bating, pickling, tanning, fatliquoring, tumbling, dyeing and drying. The entire tanning process took five days. The thicknesses of the leathers were measured with thickness gauge after tanning, and they had reduced by an average of $2 \mathrm{~mm}$ each compared to the hides. They measured approximately $2.23 \mathrm{~mm}, 3.14 \mathrm{~mm}$ and $6.00 \mathrm{~mm}$.

Experiment 1: Modeling leather mask with wooden mould using leather thickness of 2.23mm

With Ceiba wood (Ceiba pentandra) an aesthetic mask mould was carved to project details in both raised and sunk relief effects, and the surface was sanded with 180 grit of sand paper. Simple tools employed were human hands, mortar, pestle, modeling spatulas, carving tools, scissors, thumb pins, rubber mallet, punch and needle. The $2.23 \mathrm{~mm}$ thickness of leather was soaked for 12 hours in a plastic bucket to rehydrate and render it soft. The mould was laid on a table and the leather was spread over the mould and cut to size. The leather was pounded on the flesh side for 10 minutes to open up the fibers in order to make it supple and soft. It was then positioned on the mould and aligned for pre-picking of the projected relief details. The leather was covered with polyethane and left on the mould overnight to set on the mould. With the hand and spatulas, the minor details were carefully picked, and the leather surface was burnished for refined projection of the sunk and lower relief details. As the moisture content reduced appreciably to bone dry state, the leather surface was smoothened and the tension was released. The leather was exposed to dry on the mould to permanently assume the shape of the mould. Finally, the leather was removed from the wooden mould to obtain the first leather mask.

Finishing of the leather mask was carried out by trimming the rim and attaching a hard ring cut from strawboard to the interior circumference of the leather mask to reinforce it. The ring was lined with leatherette and thonged decoratively. The leather mask was polished with wax to look glossy and to enhance the aesthetics.

Experiment 2: Modeling leather mask with clay mould using leather thickness of 4.44mm

In this experiment, clay was used to create an aesthetic mask to serve as the mould for modeling leather mask. It was bisque fired and the surface was smoothened with emery cloth. The tools used in experiment 1 were employed. Leather with thickness of $4.44 \mathrm{~mm}$ was soaked for 18 hours in a plastic bucket to rehydrate and soften up. The mould was laid on a table and the leather was spread over the mould and cut to size. With pestle and mortar, the leather was pounded on the flesh side for 15 minutes to open up the fibers and become supple and soft. The leather was spread over the clay mould, aligned in position and the projected details were pre-picked in relief. As the moisture content reduced after covering the leather with polyethane and leaving it overnight to set, both the sunk and raised relief details were worked out with spatulas. Following the final steps discussed in experiment 1, the leather was removed from the clay mould after all the neces- 
Viability of indigenous vegetable tanned leather for mask production... 72

sary manipulations were carried out to attain the second leather mask.

The leather mask was enhanced through at the finishing stages by trimming the rim and attaching a hard ring cut from strawboard to the interior circumference for reinforcement as found in experiment 1. The ring was lined with leatherette and thonged to decorate the mask. The mask was given stitching effect with nylon cord within the linear sunk relief details. Finally, the surface was polished with wax.

Experiment 3: Modeling leather mask with Plaster of Paris (PoP) mould using leather thickness of $6.00 \mathrm{~mm}$

Unlike experiment 1 and 2, this experiment was carried out using a mask mould produced with Plaster of Paris (PoP). The leather used (measuring $6.00 \mathrm{~mm}$ in thickness) was soaked in water for 24 hours to assume the level of softness expected through rehydration. The tools used in experiments 1 and 2 were employed. To attain the required pliability and suppleness in the leather to facilitate the modeling process, pounding was done for 25 minutes. The leather was spread on the mould, aligned in position and worked out with the tools following the processes described in experiments 1 and 2. When all details were clearly defined and refined, the leather was removed from the PoP mould to obtain the third leather mask. The rim was trimmed and reinforced with strawboard and the surface was polished with wax.

\section{DISCUSSION OF RESULTS}

The Ghanaian indigenous vegetable tanning process employed converted the raw hide into leather which was well conditioned for modeling leather mask. The major properties needed in the leather to make it more favourable for modeling such as softness, suppleness and mouldability were achieved. Throughout the systematic processing of the hides, the researchers controlled all parameters, such as the selection of chemicals, amount of chemicals used, timings and level of chemical absorption at the generic stages including soaking, liming, defleshing, dehairing, deliming, bating, pickling, tanning, fatliquoring, tumbling, dyeing and drying. The average reduction of $2 \mathrm{~mm}$ thickness found with the leather after tanning was due to the removal of unwanted materials from the adipose layer of the pelt. The flesh contained varying amounts of fatty adipose tissue, blood vessels, nerves and voluntary muscles which could serve as barriers to the penetration of chemicals that inhibit the tanning process.

Results of experiment 1: Modeling leather mask with wooden mould (leather thickness: $2.23 \mathrm{~mm}$ )

The use of ceiba wood (ceiba pentandra) for carving the mask used as a mould made it easy to project the aesthetic details using the concept of both raised and sunk relief effects. regarding the simple tools employed, the human hand as well as the spatulas made the modeling process less cumbersome. since the leather was $2.23 \mathrm{~mm}$ in thickness, soaking it for 12 hours gave adequate duration for rehydration to take place satisfactorily, and consequently rendering the leather soft. when pounded for 10 minutes, the leather exhibited its mouldability, especially when the fibers opened up to facilitate easy depiction of the high and medium relief impressions of the mould to project as soon as it was spread for pre-picking.

When the leather was covered with polyethane and left on the mould overnight, it was observed that the leather clinged tightly and begun to set as its moisture started setting and dehydrating. By working out the minor details carefully, for refined projections of the sunk and lower relief details, the leather surface was smoothened and the tension was released for a definite shape of the mask. Since it was the first experiment, removal of the leather from the wooden mould was difficult after it was exposed to dry on the mould and became hard. When removed finally from the mould, the leather had replicated all the features of the wooden mask and the semblance was exactly identical aesthetically. The ring attached to the 
rim of the leather mask reinforced it and gave it a decorative touch, particularly with the thonging and application of wax polish. Comparatively the leather mask looked more enhanced as shown in Plates: 1 (a) and (b).

Unlike experiment 1 , the use of clay mould for modeling leather mask presented another experience. Since the clay mask used as mould was creatively made with well defined relief projections and depressions, picking the details with leather was found to be a simple task. The bisque fired nature of the clay mould created advantageous water resistance when the wet leather was spread on the mould. Due to the $4.44 \mathrm{~mm}$ thickness of leather used it took 18 hours of soaking to rehydrate and soften up. Also, as a result of the thickness, pounding was done for 15 minutes to open up the fibers to make the leather adequately supple and soft for modeling. Compared with experiment 1 where it took 10 minutes, 5 minutes difference was allowed. Relatively, moisture retention of leather was found slightly higher than the $2.23 \mathrm{~mm}$ thickness employed in experiment 1 , since loss of water was gradual. When the leather was dried, it became harder than experienced in experiment 1 , hence, removal from the clay mask mould was also found moderately difficult. The stitching effect given to the leather mask with nylon cord within the linear sunk relief details, as well as the surface polishing with wax improved the aesthetics of the leather mask as shown in Plate 2.

\section{Results of Experiment 3: Modeling leather mask with Plaster of Paris (PoP) mould} (Leather thickness: $6.00 \mathrm{~mm}$ )

The use of Plaster of Paris (PoP) mask as a mould shows another option of varied forms of possible materials that can be used for modeling leather mask. The waterproof nature of PoP and the smoothness of the surface together made it feasible to produce the leather mask. Regarding the $6 \mathrm{~mm}$ thickness of leather employed, soaking duration took 24 hours to as-

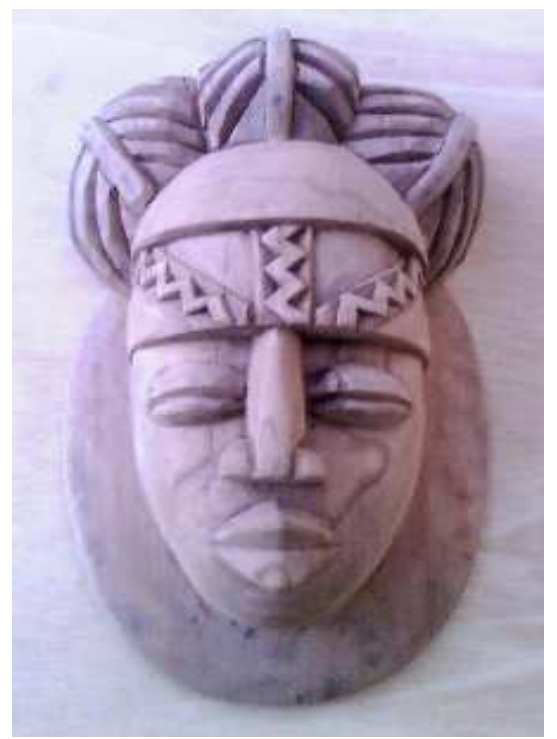

(a)

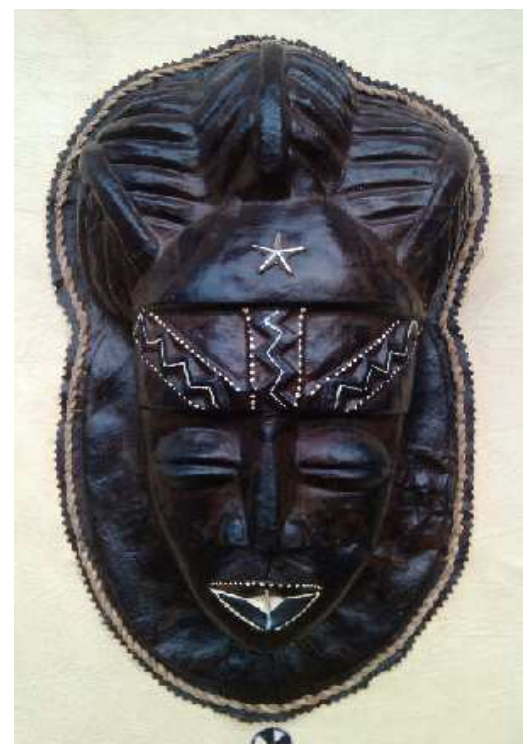

(b)

Plates 1: (a) and (b): Display of wooden mould and replicated leather mask 
Viability of indigenous vegetable tanned leather for mask production... 74

assume the level of rehydration and softness expected. In addition, due to the thickness, it required 25 minutes to pound the leather to pliability and suppleness in the leather to facilitate the modeling process. Manipulation of the sunk relief details with the hand and spatulas was found fairly difficult. In removing the leather when all details were clearly defined and refined, the leather became dry and very hard like wood. Although manipulating and working out the details was difficult, the $6 \mathrm{~mm}$ thick leather resulted in leather mask that could be equated somehow with wood in terms of hardness. When polished, the leather mask obtained look pleasant as exhibited in Plate 3.

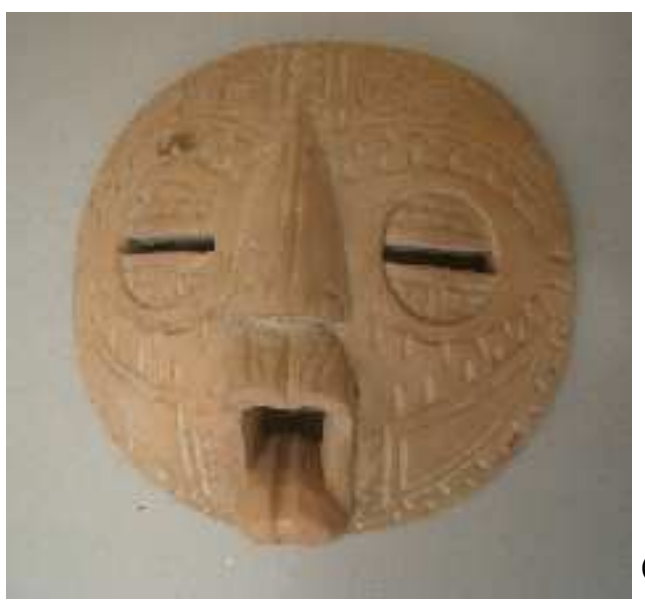

(a)

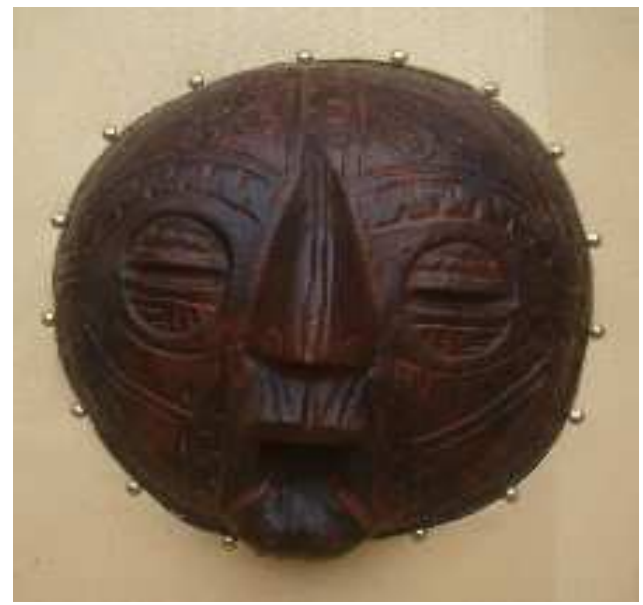

(b)

Plates 2: (a) and (b): Display of clay mould and replicated leather mask

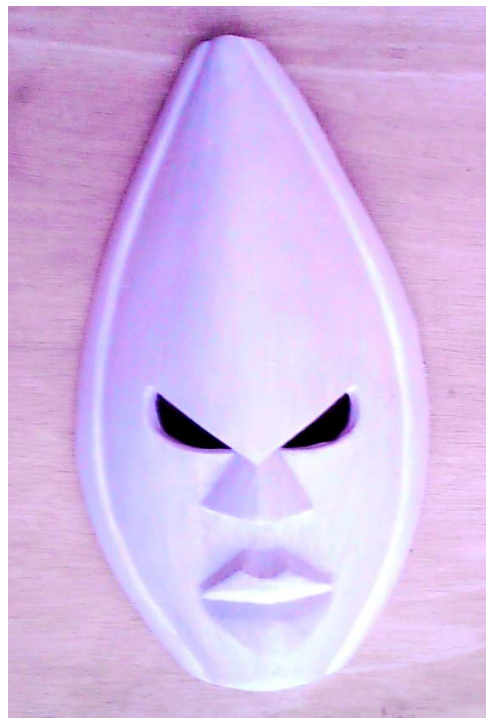

(a)

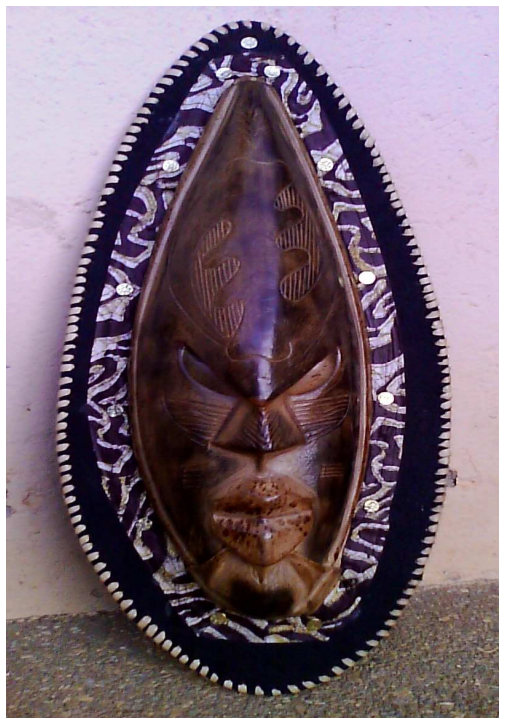

(b)

Plates 3: PoP mask mould (a) and resulting leather mask modeled (b)

Journal of Science and Technology @ C KNUST December 2014 


\section{CONCLUSION}

The experimentation of leather mask production using the soft sculpture technique of modeling has proven that with any moulds fashioned in clay, wood, PoP or other favourable materials like cement, leather can be conditioned and molded into mask possessing all the necessary aesthetic qualities. With a single mould several pieces of mask can be produced by replication.

The experiments have shown that the thickness of leather can influence the modeling process of leather mask in terms of the rate of rehydration, rate of pounding to soften and render the leather supple and hardness of leather mask obtained. Different moulds fashioned in wood, clay and Plaster of Paris can be employed in modeling leather masks.

The outcome of the study has confirmed the versatility of leather as an alternative material apposite for mask production towards reducing the pressure on wood demand for carving, as well as the sustenance of the economic value of the businesses associated with mask production. Also the study has strategically created another impetus in diversifying and expanding the utility of Ghanaian indigenous vegetable tanned leather aside the conventional use for bags, sandals and footrests. This will hopefully boost the economic relevance of the leather industry both at the local and international markets.

\section{RECOMMENDATIONS}

The concept of leather mask production as a means of creating alternative material to reduce the high dependency and pressure on wood should be embraced and enhanced to create dynamic sustainable economic opportunities for mask makers.

Wood carvers and artisans need to be educated and empowered through seminars, workshops and training activities towards skill acquisition and capacity building in leather mask production. This will equip them to stay in business even when wood is not easily available, accessible and affordable.

It is also recommended that further research into the hardening processes and embellishing techniques of leather masks for enhanced aesthetics is eminent to resonate and personify the hardness of wood.

\section{REFERENCES}

Ackah, H. and Amankwah, G. (2010). Patronage Frequency of Ghanaian Handicrafts. Unpublished Manuscript, Dept of IRAI, KNUST, Kumasi.

Agyeman, K. K. (2010). Creative Integration of Metal into Wood Art Forms. PhD Dissertation, Department of General Art Studies, KNUST, Kumasi.

Amenuke, S. K. (1995). Notes on General Knowledge in Art and Vocational Skills for Senior Secondary Schools and Teacher Training Colleges. Kumasi: KNUST Press.

Anini, F., Asubonteng K. and Boahin, J. O. B. (2012). Exploring Leather as Alternative Material for the Production of Instructional Media for Preschool Education. International Journal of Innovative Research and Development, 1(5): 39-50.

Boahin, J. O. B. (2008). Technical Problems and Solutions in the Indigenous Leather Industry: Implications for Art Education in Ghana. KNUST, Kumasi: Unpublished Ph.D Dissertation, Dept. of General Art Studies.

Collins English Dictionary. (2008). Bishopbriggs, Glasgow: HarperCollins Publishers.

Darko, K. (2006). Woodcraft Opportunities in Ghana. Unpublished Manuscript. IRAI, KNUST.

Lawson, A. (1990). Skins and Hides for Leather, $3^{\text {rd }}$ Edition; AAK Publishers Alba. 
Viability of indigenous vegetable tanned leather for mask production... 76

Okrah, E. (2002). The Growth of Wood Carving Industry in Ghana and its Threat to Selected Tree Species. Master's Thesis, Lund Sweden.
Sharphouse, J. H. (1995). Leather Technician's Handbook, LPA 75th Anniversary Edition. Northampton, UK: Leather Producers' Association. 